\title{
Cognitive Impairment among Elderly Patients Admitted For Post-Acute Care in Bahrain
}

\author{
Khaled A Abulsaad, Mahmood K Alsaeed, Mona A AlMahmoud \\ Salmaniya Medical Complex.Ebrahim Khalil Kanoo Community Medical Center (EKKCMC, \\ Ministry of Health, Kingdom of Bahrain
}

\begin{abstract}
Cognitive impairment is common in eldery patients admitted to subacute rehabilitation centres and is related to poor outcomes in terms of rehabilitation. The current study is designed to retrospectively describe the results of the assessment of a group of patients admitted to Ebrahim Khalil Kanoo Community Medical Center (EKKCMC), a Postacute care facility in Bahrain.

Using different tools, the prevalence of cognitive impairment and its common determinants amongst the group of elderly patients included in this study were assessed.

Cognitive assessment that was routinely performed in the EKKCMC for elderly patients on admission as a part of comprehensive Geriatric Assessment, full comprehensive review of cognition faculties, mood, dependency levels, social status, and full medical assessment of comorbidities and drug history were additionally utilized for this study. The main objectives were to carry out a study on the profile of elderly patients 60 years old and above that have been diagnosed with cognitive impairment upon admission to the EKKCMC. The aim of the study was to highlight the following: (1), the prevalence of cognitive impairment in the patient cohort. (2), the percentages of newly diagnosed patients versus patients with known cognitive impairment, (3) the severity of cognitive impairment, (4) associated comorbidities and mood problems, (5) the effect of cognitive impairment on functional status and the length of stay of the patient in the EKKMC.
\end{abstract}

Keywords: cognitive impairment, dementia, screening, sub-acute care, elderly, geriatric

\section{Background}

Globally, the percentage of older adults (60 years and above) is increasing and it is projected to reach $28.1 \%$ of the total population of the Kingdom of Bahrain by $2050^{[1]}$. Due to lack of awareness of healthcare professionals and patients alike in the developing world most of cognitive impairment cases remain undiagnosed. A study carried out by Chodosh et al. (2004) showed that healthcare professionals were unaware of the prevalence of a cognitive impairment in more than 40 percent of their cognitively impaired patient ${ }^{[2]}$. In another study, Kotagal et al. (2014) reported that for more than half of patients diagnosed with dementia, a proper clinical cognitive evaluation had not been performed by healthcare professionals ${ }^{[3]}$. Failure to carry out a proper assessment of cognitive function of the elderly is most likely to hinder the treatment of cognitive impairment and other comorbid conditions, with the cognitive condition worsening over time in most cases ${ }^{[4]}{ }^{[5]}{ }^{[6]}{ }^{[7]}$. Factors that influence the frequent admissions of dementia patients are different than those that result in long-term hospitalization of the patient ${ }^{[8]}$. An increase in the length of hospitalization of patients suffering from dementia was mostly as a result of the effects of dementia on mobility, continence, nutrition of the patient as well as delirium and low-quality of social life ${ }^{[9]}$. This study was performed in a post-acute medical care facility, the Ebrahim Khalil Kanoo Community Medical Center (EKKCMC) which can be described as a post-acute medical care center that provides care for patients in the post-acute stage but not for long term care. In order to best describe EKKCMC, inpatient services that operate at a different level to acute or long-term care are described as "intermediate care" [10] [11]. Sub-acute care is generally more intensive than in a traditional nursing care facility ${ }^{[12]}$. EKKCMC provides care to all age groups, yet over $80 \%$ of patients receiving care in this facility are elderly with the average age being about 60 years old.

Cognitive impairment has a major impact on the quality of life of elderly persons. Understanding the epidemiology of cognitive impairment in a given 
population is crucial for adequate planning of proper healthcare strategies to deal with such cases. Thus, this study was designed to assess the prevalence of cognitive impairment in elderly admitted in the EKKCMC for a 6-month period.

\section{Methods}

This study is a retrospective study in which the medical records of elderly patients were reviewed for a 6-month period from December 2015 to May 2016. The patient cohort consisted of both male and female participants that were 60 years old and above admitted to the EKKCMC during this time period. Patients were included in the cohort based on age, we looked at the screening tests done routinely for cognitive impairment as part of comprehensive geriatric assessment of which the following were taken into consideration: The minimental state examination (MMSE) ${ }^{[13]}$, the short portable mental status questionnaire (SPMSQ) ${ }^{[14]}$ and the clock drawing test (CDT) ${ }^{[15]}$. The past history of the patient as well as clinical assessment performed upon diagnosis on admission and discharge were equally reviewed. Additionally, records were reviewed with regards to screening tests that performed for functional status using the Barthel index for Activities of Daily living (ADL) ${ }^{[16]}$, the Geriatric Depression Scale (GDS) ${ }^{[17]}$, and brain CT scans done around the admission dates. Determinants for cognitive impairment and correlation with other comorbidities, medications and length of stay as well as destination of discharge were also recorded. The maximum MMSE score is 30 . A score of between 20 to 24 suggests mild dementia, 13 to 20 suggest moderate dementia and $<12$ indicates severe dementia. For the SPSMSQ score, the following parameters were taken into consideration: 0-2 errors: normal mental functioning, 3-4 errors: mild cognitive impairment, 5-7 errors: moderate cognitive impairment and 8 or more errors: severe cognitive impairment. One or more errors will be allowed if the patient has had a grade school education or less. One less error is allowed if the patient has had an education beyond the high school level. CDT was performed on a scale of 1-10. A cut of score of $<5$ is indicative of cognitive impairment.

\section{Statistical Methods}

Statistical analysis was performed using SPSS. A Spearman correlation test was used for data analysis. A $\mathrm{P}<0.05$ was accepted as an indicator for significance in all comparisons.

\section{Results}

In this study, the mean (SD) age of patients was 75.59 (9.32). The study included 51 elderly patients whereby twenty-three were females $(45.1 \%)$ and twenty-eight were males $(54.9 \%)$. The mean MMSE of patients was 16.34 (8.95), while a mean of 5.80 (3.05) was recorded for the SPMSQ) with the mean CDT estimated to be approximately 2.26 (2.06). The prevalence of cognitive impairment in the study cohort was assessed by MMSE with $67.7 \%$ of the patients being diagnosed with this test compared to $72.5 \%$ of the patients diagnosed with the SPMSQ test. Of the 45 participants, six illiterate participants were excluded from the CDT test and the prevalence of cognitive impairment was estimated at $64.4 \%$ (Table 1). Taken together, these results suggest in at least two of the tests used for the assessment of cognitive impairment, $58.8 \%$ of the study participants were cognitively impaired. The mean age of study participants that were cognitively impaired was recorded as $78.70(+/-8.65)$ while the mean age of those with whereby no cognitive impairment was recorded to be 71.14 (8.59). None of the cognitively impaired study participants had a history or previous diagnosis for cognitive disorders.

\begin{tabular}{|c|c|c|c|c|}
\hline & \multicolumn{4}{|c|}{$\begin{array}{c}\text { Cognitive impairment by } \\
\text { MMSE }\end{array}$} \\
\hline & & $\begin{array}{l}\text { yes } \\
(n=33)\end{array}$ & $\begin{array}{l}\text { No } \\
(n=18)\end{array}$ & $\begin{array}{l}\text { Significance } \\
\text { association }\end{array}$ \\
\hline \multirow[b]{2}{*}{ SPMSQ } & $\begin{array}{l}\text { Cognitively } \\
\text { impaired } \\
(\mathrm{n}=37)\end{array}$ & $33(100 \%)$ & $4(22.2 \%)$ & \multirow[t]{2}{*}{$\begin{array}{l}\mathrm{r}^{2}=40.875 \\
P=0.000\end{array}$} \\
\hline & $\begin{array}{l}\text { Not- } \\
\text { cognitively } \\
\text { impaired } \\
(n=14)\end{array}$ & $0(0 \%)$ & $14(77.8 \%)$ & \\
\hline \multirow{3}{*}{$C D T$} & $\begin{array}{l}\text { Cognitively } \\
\text { impaired } \\
(n=29)\end{array}$ & $25(75.8 \%)$ & $4(22.2 \%)$ & \multirow[t]{3}{*}{$\begin{array}{l}r 2=22.105 \\
P=0.000\end{array}$} \\
\hline & $\begin{array}{l}\text { Not- } \\
\text { cognitively } \\
\text { impaired } \\
(\mathrm{n}=16)\end{array}$ & $3(9.1 \%)$ & $13(72.2 \%)$ & \\
\hline & $\begin{array}{l}\text { Not done } \\
(\mathrm{n}=6)\end{array}$ & $5(15.2 \%)$ & $1(5.6 \%)$ & \\
\hline
\end{tabular}

SPMSQ, the short portable mental status questionnaire, CDT (clock drawing test) and MMSE, The mini-mental state a...nminastinn

There was no correlation observed between gender and the prevalence of cognitive impairment within the group $\left(\mathrm{X}^{2}=1.996\right.$ and $\left.\mathrm{P}=0.158\right)$. We also observed no significant association between the prevalence of cognitive impairment and the educational level of the patients $\left(r^{2}=2.669, P=0.286\right)$. There was a strong correlation between marital status and diagnosis of cognitive impairment within the patient group. Of the 25 widowed patients $19(74 \%)$ were diagnosed of having cognitive impairment while 6 of the patients $(24 \%)$ had no cognitive impairment $\left(\mathrm{r}^{2}=8.446, P=\right.$ $0.015)$. There were no significant differences observed among married participants with $45.8 \%$ of the respondents diagnosed with cognitive impairments as 
opposed to only about $54.2 \%$ of the respondents not diagnosed with a cognitive impairment. 20 out of the 51 $(39.2 \%)$ participants in the study were classified as being depressed. $80 \%$ of patients that were depressed were diagnosed with cognitive impairments $\left(r^{2}=6.404\right.$ $P=0.011)$ with $24 \%$ of the depressed patients observed as not having any cognitive disorders (Table 2).

Table 2: Comparison of the diagnosis of cognitive impairment relative to the patient's demographic characteristics

\begin{tabular}{|c|c|c|c|}
\hline Variable & $\begin{array}{l}\text { Cognitively } \\
\text { impaired } \\
(\mathbf{N}=\mathbf{3 0})\end{array}$ & $\begin{array}{l}\text { Not } \\
\text { cognitively } \\
\text { impaired } \\
(\mathrm{N}=21)\end{array}$ & $\begin{array}{l}\text { Significant } \\
\text { associations }\end{array}$ \\
\hline & $\mathrm{N}(\%)$ & $\mathrm{N}(\%)$ & \\
\hline $\begin{array}{l}\text { Gender } \\
\text { Male } \\
\text { Female }\end{array}$ & $\begin{array}{l}14(50 \%) \\
16(69.6 \%)\end{array}$ & $\begin{array}{l}14(50 \%) \\
7(30.4 \%)\end{array}$ & $\begin{array}{l}\mathrm{r} 2=1.996 \\
\mathrm{P}=0.158\end{array}$ \\
\hline $\begin{array}{l}\text { Education } \\
\text { Illiterate } \\
\text { Read and } \\
\text { write } \\
\text { High School }\end{array}$ & $\begin{array}{l}5(83.3 \%) \\
17(60.7 \%) \\
8(47.1 \%)\end{array}$ & $\begin{array}{l}1(16.7 \%) \\
11(39.3 \%) \\
9(52.9 \%)\end{array}$ & $\begin{array}{l}r 2=2.669 \\
P=0.286\end{array}$ \\
\hline $\begin{array}{l}\text { Marital } \\
\text { state } \\
\text { Single } \\
\text { Married } \\
\text { Widowed }\end{array}$ & $\begin{array}{l}0(0 \%) \\
11(45.8 \%) \\
19(76 \%)\end{array}$ & $\begin{array}{l}1(100 \%) \\
14(54.2 \%) \\
6(24 \%)\end{array}$ & $\begin{array}{l}\mathrm{r} 2=8.446 \\
\mathrm{P}=0.015\end{array}$ \\
\hline $\begin{array}{l}\text { Depressed } \\
(\mathrm{n}=20 / 51)\end{array}$ & $16(80 \%)$ & $4(20 \%)$ & $\begin{array}{l}r 2=6.404 \\
P=0.011\end{array}$ \\
\hline
\end{tabular}

Analysis to determine the correlation between MMSE, age, GDS and the Barthel index for Activities of Daily living (ADL) were performed. A positive correlation among MMSE, age, SPMSQ, CDT and the Barthel index for Activities of Daily living (ADL) was observed. Among the listed variables, MMSE was most strongly correlated to SPMSQ $(\mathrm{r} 2=0.846)$ and the Barthel index for Activities of Daily living (ADL) (r2= 0.713) (Table 3).

Table 3: Correlation of MMSE with age, SPMSQ, CDT, GDS and the Barthel score

\begin{tabular}{lll}
\hline & MMSE & \\
\hline Age & $\mathrm{r} 2=-0.535$ & $\mathrm{P}=0.000$ \\
SPMSQ & $\mathrm{r} 2=-0.846$ & $\mathrm{P}=0.000$ \\
CDT & $\mathrm{r} 2=0.684$ & $\mathrm{P}=0.000$ \\
GDS & $\mathrm{r} 2=-0.647$ & $\mathrm{P}=0.000$ \\
Barthel index & $\mathrm{r} 2=0.713$ & $\mathrm{P}=0.000$ \\
\hline
\end{tabular}

SPMSQ, the short portable mental status questionnaire, CDT (cognitive dependency test), GDS, Geriatric Depression Scale and MMSE, The mini-mental state examination.

\section{Discussion}

Several studies have recorded an increased incidence of cognitive impairment in the elderly ${ }^{[18][19]}$. Our findings have demonstrated comparative results with the percentage of the elderly being diagnosed with cognitive impairment being significantly high. The fact that we observed a significantly higher percentage of the patients in the study being diagnosed with cognitive impairment could be attributed to certain factors that were taken into consideration upon inclusion of the study participants in the cohort. Participants were enrolled in the study only if they were classified as post-acute cases, defined by their admission to acute care hospitals for lengthy periods of time (greater than 1 month of hospitalization). Long-term hospitalization has been observed to be one of the factors that has been linked to cognitive impairment in the elderly ${ }^{[20]}$. All patients found to be cognitively impaired were not screened for dementia during the period of acute hospitalization or before. This was not taken into consideration as one of the pre-conditions that could be the cause of incomplete patient response to acute management for example, a failure of mobilization after surgery or stroke of the patient. Of the respondents assessed in this study, about $58 \%$ of the patients were classed as having cognitive disorders. In our study, there was a strong correlation between marital status, depression and the prevalence of cognitive impairment being highest between widowed and depressed patients. A study conducted by Feng et al. (2014) showed that being single or widowed was associated with an increased risk of cognitive impairment in an elderly Chinese population. This risk was more prevalent in the male participants in the study cohort ${ }^{[21]}$. These findings suggest that relationships, such as marriage are somewhat beneficial towards cognitive function.

The relationship between marital status and cognitive impairment might be explained by the fact that being married might relieve feelings of stress and loneliness which might protect individuals from developing cognitive impairment later in life ${ }^{[22][23][24]}$. Depression and dementia are mental health disorders that are most often encountered in the elderly. The rates of depression and dementia in the elderly have been reported to be between 9 to $68 \%$ in India ${ }^{[25]}$. A depressive disorder can be defined as the occurrence of depressive moods, reduced energy and a loss of interest in daily activities ${ }^{[26]}$. Growing evidence has speculated that depression might be one of the main factors that might enhance the prevalence of cognitive disorders in the elderly ${ }^{[27]}$. Recent studies have shown that patients with late-onset depression have developed dementia a few years after diagnosis ${ }^{[28]}$. The positive relationship observed between depression and the development of cognitive impairment might be as a result of other risk factors such as genetic and environmental determinants ${ }^{[26]}$. The increased risk of developing cognitive 
impairment due to acute hospital care of the elderly was reported to be associated with delirium, medication, stress and depression, the later which was strongly correlated to the prevalence of cognitive impairment as reported in our study ${ }^{[29]}{ }^{[30]}$. The prevalence of cognitive decline in the elderly is grossly under reported even though there exist several screening tools such as the MMSE that facilitate the rapid diagnosis of cognitive decline in the elderly ${ }^{[31]}$.

There were several limitations in this study, firstly the sample size was relatively small (51 participants). It will be advisable to expand the patient cohort in order to improve the robustness of the data. The MMSE tool is an adequate tool for the screening of dementia in adults with minimum literacy competencies. However, research variability has been observed in elderly patients that are illiterate and this might have serious consequences for clinical practice and research studies carried out in low income countries where there is a high prevalence of illiteracy among the elderly ${ }^{[32]}$. The successful completion of this study will aid in the formulation of proper diagnostic methodologies and the evaluation of the impact of cognitive decline of the elderly population in Bahrain.

Still a question not answered: what was the cognitive status of those patients before admission to acute care and whether the acute condition had contributed to that high prevalence of cognitive impairment in our sample, or was cognitive impairment the cause of prolonged hospitalization in acute care and the need of admission for sub acute care?

\section{Conclusion:}

This study was performed in order to assess the prevalence of cognitive decline in the elderly admitted in a post-acute care facility. We observed that cognitive disorders were strongly correlated to the marital status, poor function and depression. Cognitive impairment of the elderly presents a challenging issue with regards to the proper management of elderly patients during acute care admission. Patient medical history and additionally screening for cognitive disorders are essential to properly diagnose cognitive impairment as one of the causes of failure to discharge these patients during acute care hospitalization. Healthcare professionals involved in the proper management of elderly patients should be aware of the prevalence of cognitive impairment and dementia in the elderly and should undergo training on how and when to refer these patients for screening of cognitive disorders. Assessment of cognitive status during hospitalization in acute care facilities should be encouraged whenever patient condition enables that assessment.

\section{References}

1. Khan, H. T. A., Hussein, S., \& Deane, J. (2017). Nexus Between Demographic Change and Elderly Care Need in the Gulf Cooperation Council (GCC) Countries: Some Policy Implications. Ageing International, 42(4), 466-487. https://doi.org/10.1007/s12126-017-9303-9

2. Chodosh, J., Petitti, D. B., Elliott, M., Hays, R. D., Crooks, V. C., Reuben, D. B., ... Wenger, N. (2004). Physician Recognition of Cognitive Impairment: Evaluating the Need for Improvement. Journal of the American

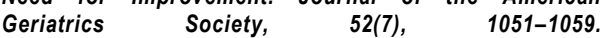
https://doi.org/10.1111/j.1532-5415.2004.52301.x

3. Kotagal, V., Langa, K. M., Plassman, B. L., Fisher, G. G., Giordani, B. J., Wallace, R. B., ... Foster, N. L. (2015). Factors associated with cognitive evaluations in the United States. Neurology, 84(1), 64 LP - 71. https://doi.org/10.1212/WNL.0000000000001096

4. Boustani, M., Peterson, B., Hanson, L., Harris, R., \& Lohr, K. N. (2003). Screening for Dementia in Primary Care: $A$ Summary of the Evidence for the U.S. Preventive Services Task Force. Annals of Internal Medicine, 138(11), 927-937. https://doi.org/10.7326/0003-4819-13811-200306030-00015

5. Bradford, A., Kunik, M. E., Schulz, P., Williams, S. P., \& Singh, $H$. (2009). Missed and delayed diagnosis of dementia in primary care: prevalence and contributing factors. Alzheimer Disease and Associated Disorders, 23(4), 306314. https://doi.org/10.1097/WAD.0b013e3181a6bebc

6. Galvin, J. E., \& Sadowsky, C. H. (2012). Practical Guidelines for the Recognition and Diagnosis of Dementia. The Journal of the American Board of Family Medicine, 25(3), 367382. https://doi.org/10.3122/jabfm.2012.03.100181

7. Pandharipande, P. P., Girard, T. D., Jackson, J. C., Morandi, A., Thompson, J. L., Pun, B. T., ... Ely, E. W. (2013). LongTerm Cognitive Impairment after Critical IIIness. New England Journal of Medicine, 369(14), 1306-1316. https://doi.org/10.1056/NEJMoa1301372

8. Rudolph, J. L., Zanin, N. M., Jones, R. N., Marcantonio, E. R., Fong, T. G., Yang, F. M., ... Inouye, S. K. (2010). Hospitalization in Community-Dwelling Persons with Alzheimer's Disease: Frequency and Causes. Journal of the American Geriatrics Society, 58(8), 1542-1548. https://doi.org/10.1111/j.1532-5415.2010.02924.x

9. Lang, P. O., Zekry, D., Michel, J. P., Drame, M., Novella, J. L., Jolly, D., \& Blanchard, F. (2010). Early markers of prolonged hospital stay in demented inpatients: $A$ multicentre and prospective study. Journal of Nutrition, Health and Aging, 14(2), 141-147. https://doi.org/10.1007/s12603-009-0182-y

10. MacMahon D 2001. "Intermediate care-a challenge to specialty of geriatric medicine or its renaissance?" Age and ageing 30 Suppl 3: 19-23

11. Steiner A 2001. "Intermediate care-a good thing?" Age Ageing 30 Suppl 3: 33-9

12. Flintoft $V F$ \& Williams $J I$ et al. 1998. "The need for acute, subacute and nonacute care at 105 general hospital sites in Ontario. Joint Policy and Planning Committee NonAcute Hospitalization Project Working Group." Cmaj 158(10): 1289-96.

13. Folstein MF, Folstein SE, McHugh PR (1975). Mini-Mental State: a practical method for grading the cognitive state of patients for the clinician. J Psychiatr Res 12:189-98.

14. Pfeiffer, E. (1975). A Short Portable Mental Status Questionnaire for the Assessment of Organic Brain Deficit in Elderly Patientst. Journal of the American Geriatrics Society, 23(10), 433-441. https://doi.org/10.1111/j.1532-5415.1975.tb00927.x

15. Shulman KI, Gold DP, Cohen CA, et al (1993). Clock drawing and dementia in the community: a longitudinal study. Int $J$ Geriatr Psych ;8:487-96.

16. Mahoney, F. I., \& Barthel, D. W. (1965). Functional evaluation: The Barthel Index: $A$ simple index of independence useful in scoring improvement in the rehabilitation of the chronically ill. Maryland State Medical Journal. US: Medical and Chirurgical Faculty of the State of Maryland.

17. Sheikh, J. I., \& Yesavage, J. A. (1986). Geriatric Depression Scale (GDS): Recent evidence and development of a 
shorter version. Clinical Gerontologist: The Journal of Aging and Mental Health. US: Haworth Press. https://doi.org/10.1300/J018v05n01 09

18. Al-Jawad M, Rashid A. K, \& Narayan K. A. (2007). Prevalence of undetected cognitive impairment and depression in residents of an elderly care home. Medical Journal of Malaysia, 62(2), 375-379.

19. Arias-Merino, E. D., Orozco-Mares, I., Garabito-Esparza, L. C., Fernandez-Cruz, L., Arias-Merino, M. J., de la Rosa, A., ... Gonzalez-P Rez, G. J. (2003). Correlates of cognitive impairment in elderly residents of long term care institutions in the metropolitan area of Guadalajara, Mexico. The Journal of Nutrition, Health \& Aging, 7(2), 97-101.

Retrieved http://europepmc.org/abstract/MED/12679829

20. Mathews, S. B., Arnold, S. E., \& Epperson, C. N. (2014). Hospitalization and cognitive decline: Can the nature of the relationship be deciphered? The American Journal of Geriatric Psychiatry: Official Journal of the American Association for Geriatric Psychiatry, 22(5), 465-480. https://doi.org/10.1016/j.jagp.2012.08.012

21. Feng, L., Ng, X.-T., Yap, P., Li, J., Lee, T.-S., Håkansson, K., ... Ng, T.-P. (2014). Marital Status and Cognitive Impairment among Community-Dwelling Chinese Older Adults: The Role of Gender and Social Engagement. Dementia and Geriatric Cognitive Disorders Extra, 4(3), 375-384. https://doi.org/10.1159/000358584

22. Boyle, P. A., Buchman, A. S., Barnes, L. L., \& Bennett, D. A (2010). Effect of a Purpose in Life on Risk of Incident Alzheimer Disease and Mild Cognitive Impairment in Community-Dwelling Older PersonsLife Purpose and $A D$ Risk. JAMA Psychiatry, 67(3), 304-310. https://doi.org/10.1001/archgenpsychiatry.2009.208

23. Johansson, L., Guo, X., Waern, M., Östling, S., Gustafson, D. Bengtsson, C., \& Skoog, I. (2010). Midlife psychological stress and risk of dementia: a 35-year longitudinal population study. Brain, 133(8), 2217-2224. https://doi.org/10.1093/brain/awq116

24. Wilson, R. S., Barnes, L. L., Aggarwal, N. T., Boyle, P. A., Hebert, L. E., Mendes de Leon, C. F., \& Evans, D. A. (2010). Cognitive activity and the cognitive morbidity of Alzheimer disease. Neurology, 75(11), 990 LP - 996. https://doi.org/10.1212/WNL.0b013e3181f25b5e

25. Muliyala, K. P., \& Varghese, M. (2010). The complex relationship between depression and dementia. Annals of Indian Academy of Neurology, 13(Suppl 2), S69-S73. https://doi.org/10.4103/0972-2327.74248
26. Ganguli, M. (2009). Depression, cognitive impairment and dementia: Why should clinicians care about the web of causation? Indian Journal of Psychiatry, 51 Suppl 1(Supp/1), S29-S34. Retrieved from https://www.ncbi.nlm.nih.gov/pubmed/21416013

27. Geerlings, M. I., den Heijer, T., Koudstaal, P. J., Hofman, A., \& Breteler, M. M. B. (2008). History of depression, depressive symptoms, and medial temporal lobe atrophy and the risk of Alzheimer disease. Neurology, 70(15), $1258 \quad$ LP $\quad$ - 1264. https://doi.org/10.1212/01.wnl.0000308937.30473.d1

28. Sheline, Y. I., Barch, D. M., Garcia, K., Gersing, K., Pieper, C., Welsh-Bohmer, K.,... Doraiswamy, P. M. (2006). Cognitive Function in Late Life Depression: Relationships to Depression Severity, Cerebrovascular Risk Factors and Processing Speed. Biological Psychiatry, 60(1), 58-65. https://doi.org/https://doi.org/10.1016/j.biopsych.2005.09. 019

29. Ahmed, S., Leurent, B., \& Sampson, E. L. (2014). Risk factors for incident delirium among older people in acute hospital medical units: a systematic review and metaanalysis. Age and Ageing, 43(3), 326-333. https://doi.org/10.1093/ageing/afu022

30. Davydow, D. S., Zatzick, D., Hough, C. L., \& Katon, W. J. (2013). In-Hospital Acute Stress Symptoms Are Associated with Impairment in Cognition 1 Year after Intensive Care Unit Admission. Annals of the American Thoracic Society, 10(5), https://doi.org/10.1513/AnnalsATS.201303-0600C

31. Teresi, J. A. (2007). Mini-Mental State Examination (MMSE): Scaling the MMSE using item response theory (IRT). Journal of Clinical Epidemiology, 60(3), 256-259. https://doi.org/10.1016/j.jclinepi.2006.06.009

32. Scazufca, M., Almeida, O. P., Vallada, H. P., Tasse, W. A., \& Menezes, P. R. (2008). Limitations of the Mini-Mental State Examination for screening dementia in a community with low socioeconomic status. European Archives of Psychiatry and Clinical Neuroscience, 259(1), 8. https://doi.org/10.1007/s00406-008-0827-6 